\title{
Real-time CMR guidance for intracardiac and great vessel pressure mapping in patients with congenital heart disease using an MR conditional guidewire-results of 25 patients
}

\author{
Christian Meierhofer ${ }^{1}$, Kristina Belker ${ }^{1}$, Nerejda Shehu ${ }^{1}$, Heiner Latus ${ }^{1}$, Naira Mkrtchyan ${ }^{1}$, \\ Susanne Naumann ${ }^{1}$, Stefan Martinoff ${ }^{2}$, Heiko Stern ${ }^{1}$, Andreas Eicken $^{1}$, Peter Ewert $^{1,3}$ \\ ${ }^{1}$ Congenital Heart Disease and Pediatric Cardiology, German Heart Center Munich, Technical University of Munich, Munich, Germany; \\ ${ }^{2}$ Radiology, German Heart Center Munich, Technical University of Munich, Munich, Germany; ${ }^{3}$ Munich Heart Alliance, Deutsches Zentrum für \\ Herz-Kreislauf-Forschung e.V., Berlin, Germany \\ Contributions: (I) Conception and design: C Meierhofer, H Stern, A Eiken, P Ewert; (II) Administrative support: C Meierhofer, N Shehu, H \\ Latus, N Mkrtchyan, S Martinoff, S Naumann, A Eiken, P Ewert; (III) Provision of study materials or patients: C Meierhofer, N Shehu, H Latus, \\ N Mkrtchyan, S Naumann, S Martinoff; (IV) Collection and assembly of data: C Meierhofer, N Shehu, H Latus, N Mkrtchyan, S Martinoff, S \\ Naumann, H Stern, A Eiken, P Ewert; (V) Data analysis and interpretation: C Meierhofer, H Stern, A Eiken, P Ewert; (VI) Manuscript writing: All \\ authors; (VII) Final approval of manuscript: All authors. \\ Correspondence to: Christian Meierhofer. German Heart Center Munich, Technical University of Munich, Lazarettstrasse 36,80636 Munich, \\ Germany. Email: meierhofer@dhm.mhn.de.
}

Background: The aim of this study was to test a CE-certified MR-conditional guidewire to facilitate blood pressure measurement in cardiovascular magnetic resonance (CMR) using fluid-filled catheters in patients with congenital heart disease (CHD). The main purpose was to determine procedural success in a post market clinical follow-up (PMCF) for routine procedure in a diagnostic and interventional workflow. Realtime CMR provides high quality imaging without the risk of exposing the patient to X-rays, especially for patients with irregular heart anatomy and patients who are susceptible to radiation and iodinated contrast media. To date, the assessment of blood pressure gradients is not a common feature of CMR, as these gradients cannot be accurately evaluated in routine CMR.

Methods: Twenty-five CHD patients who were planned for combined clinical CMR and diagnostic and/ or interventional catheterization were enrolled in the trial. Prior to inclusion, a specific procedure for catheterization in CMR was defined, encompassing the assessment of pressure and pressure gradients in the heart and great vessels.

Results: By the use of an MR-conditional guidewire we successfully measured specific pressure and pressure gradients in up to $92 \%$ of cases with liquid-filled catheters which were guided exclusively under CMR guidance. There were no guidewire-related adverse events, and guidewire guidance and manipulation of catheters were successful.

Conclusions: Using a MR-conditional guidewire assists in easily reaching targets in the heart and great vessels and makes the catheter itself visible, so that invasive blood pressure assessment by CMR guidance with liquid-filled catheters can be improved.

Keywords: Cardiovascular magnetic resonance (CMR); congenital heart disease (CHD); cardiac catheterization; magnetic resonance; pressure; guidewire

Submitted Jun 21, 2020. Accepted for publication Oct 27, 2020.

doi: $10.21037 / \mathrm{cdt}-20-575$

View this article at: http://dx.doi.org/10.21037/cdt-20-575

^ ORCID: 0000-0002-1367-3410. 


\section{Introduction}

Cardiovascular magnetic resonance (CMR) is an established instrument for measuring heart volume and blood flow using standardized methods and is increasingly replacing diagnostic cardiac catheterization, although pressure and pressure gradients cannot be accurately assessed with routine CMR (1-3). The determination of invasive pressure gradients using liquid-filled catheters in MRI studies has been rarely used in clinical settings in so-called hybrid MR fluoroscopy suites (4-6).

Thus, we aimed to test a CE-certified conditional MR guidewire to facilitate blood pressure measurement by interventional CMR (iCMR) guidance using liquid-filled catheters in CHD patients without the need for a hybrid MR fluoroscopy suite. The primary objective was to define the success of the procedure in our diagnostic and interventional workflow. The trial itself was also designed to serve as a post-market clinical follow-up (PMCF) of the guidewire.

The application of fluoroscopic techniques with the use of ionizing radiation to drive cardiac diagnostic and interventional procedures is not optimal for sensitive, especially young patients and for procedures that are timeconsuming and may even induce an enhanced risk of cancer occurrence $(7,8)$. While current imaging technologies offer many options for dose minimization, they require careful customization. Hence, real-time iCMR could offer a radiation-free option to radiographic imaging and assist in bringing diagnostic and interventional methods from the traditional catheter lab to iCMR. In addition to radiation reduction by fluoroscopy, better visibility of the specific soft tissue architecture can also improve the success of the technique (9).

In humans, MR-guided interventions have been limited by the absence of MR-compatible and safe devices, such as MR-guided guidewires. In spite of all the promising advancements made over the last decade, the iCMR community continues to need certified devices and guidewires that are appropriate for diagnostic and therapeutic purposes and allow iCMR to more effectively extend to human cardiovascular areas $(6,10)$.

There are attempts to use conventional, MR nonconditional guidewires in the MR environment by testing the equipment for heating or using low specific absorption rate. Moreover, a dedicated low gradient MR system can be used $(11,12)$.

Earlier versions of the guidewire and its markers used in this trial were evaluated in experimental animal studies and phantoms for vena cava filter positioning in the inferior vena cava and stenting in regions such as the renal arteries by magnetic resonance $(13,14)$. Lately, in studies with phantoms, similar guide wires equipped with discrete markers have been used to show that percutaneous angioplasty can also be performed under MR guidance (15). We present the following article in accordance with the MDAR reporting checklist (available at http://dx.doi. org/10.21037/cdt-20-575).

\section{Methods}

Twenty-five patients (12 women; age median 28.3 years, range 14.1 up to 79.0 years, mean age 37 years) with congenital heart disease were scheduled for diagnostic or interventional cardiac catheterization by fluoroscopy and CMR and were included into this trial. The study was designed to be a prospective, single center (initiated as a multi-center), open label trial.

Subsequent to a standard CMR examination, invasive blood pressure and pressure gradients were assessed. The target regions were defined during the enrollment process in the clinical trial. An assessment using conventional catheterization by fluoroscopy was considered on the very same day following completion of iCMR, since most patients required interventional procedures under fluoroscopic guidance. After iCMR investigation, 22 of 25 individuals had undergone standard cardiac catheterization and fluoroscopic procedures. For 3 out of 25 cases, no separate cath lab intervention was required because all clinical issues could be resolved by $\mathrm{ICMR}$ and there was no need for intervention based on ICMR results. Two very skilled interventionists carried out cardiac catheterization in iCMR.

\section{Ethics approval}

The study was approved by the ethical committee of the Technical University of Munich. The study is documented at ClinicalTrials.gov under identifier NCT02493634. All patients and parents gave their written consent to the study. The study was conducted in accordance with the Declaration of Helsinki (as revised in 2013) (16).

\section{Inclusion criteria}

Included were CHD patients with clinical indicators for CMR and standard diagnostic or interventional heart 


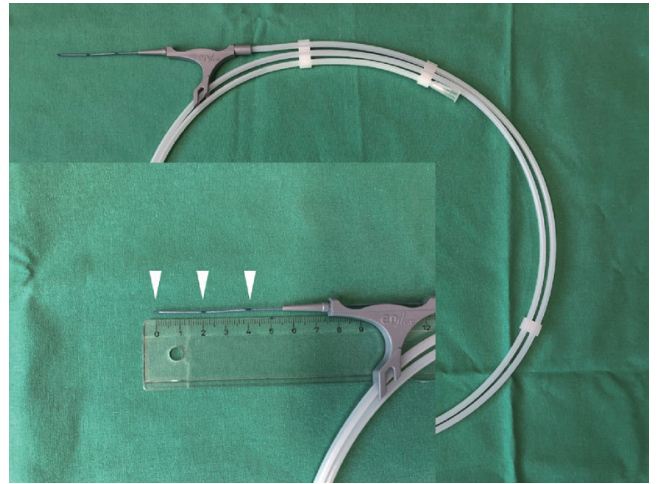

Figure 1 MRWire ${ }^{\circledR}$. Photograph of MRWire ${ }^{\circledR}$ and MRWire ${ }^{\circledR}$ tip construction with the three markers.

catheterization. A total body weight of $\geq 40 \mathrm{~kg}$ was necessary to enable the insertion of an introducer of $\geq 5$ French.

\section{Exclusion criteria}

Excluded were all patients with a medical history of major bleeding disorder, a major surgical procedure in the last 6 weeks, a contraindication for CMR, contraindications for guidewire procedures such as signs of active infection or a current pregnancy.

\section{Duration of the trial}

Postprocedural follow-up was 30 days.

\section{Blood pressure and pressure gradient mapping using liquid-filled catheters}

We were using a proprietary standard 1.5 Tesla MR scanner (Avanto, Siemens, Erlangen, Germany) to carry out the imaging for assessing pressure and pressure gradients using liquid-filled catheters.

After covering the patient with sterile drapes and puncturing the femoral artery and/or vein with a Luer lock needle (Luer lock needle REF 219.09 and REF 219.14, Vygon, Ècouen, France) on the scanner table in the scanner room, an introducer sheath (Radiofocus Introducer II, 6 Fr, Terumo Europe, Leuven, Belgium) was inserted using the Seldinger method prior to placing the patient into the bore of the scanner. A 6F-Berman angiography balloon catheter (length $90 \mathrm{~cm}$, Arrow International Inc., Reading, $\mathrm{PA})$ and an MR-compatible guidewire (specifications, see below) were then used. Patients were examined in a supine and head-first position using a 12-element cardiac phased array multi-channel coil (Siemens Healthcare, Erlangen, Germany) with a real-time sequence for visualization.

The liquid-filled catheters were attached to a pressure transducing device (CODAN Xtrans, CODAN pvb Critical Care GmbH, Forstinning, Germany) and a digital monitor (Precess Invivo, Gainesville, FL) for pressure monitoring and measurement. However, a special pressure registration device, as proposed by the NIH research group (https:// icmr.nhlbi.nih.gov), was not readily available for this trial. All catheters were utilized off-label for iCMR.

\section{Guidewire}

The study was designed to demonstrate the efficacy and overall safety of the MR-conditional guidewire (MRWire ${ }^{\circledR}$, Nano4Imaging, Düsseldorf, Germany). The guidewire has three passive markers at the tip.

The wire was developed and certified for use in the MR field (in line with standards ASTM F2182, F2052, F2053 and F2213; standard test method for medical equipment in the magnetic resonance field) and is designed as a onepiece core-shaft-tip assembly of fiber-reinforced composite material with a Pebax outer sleeve. The guidewire had a straight tip, diameter $0.89 \mathrm{~mm} / 0.35$ inch, length $180 \mathrm{~cm}$, with 3 marks at 0,2 and $4 \mathrm{~cm}$ (Figure 1). The distinctive marks on the tip produce the desired artifacts, which are tested according to ASTM 2119 (standard test method for evaluation of MR image artifacts of passive implants). Additionally, the guidewire incorporates $\mathrm{BaSO}_{4}$ for X-ray visibility. The guidewires were delivered sterile and nonpyrogenous and complied with the current product norm ISO/DIS 11070:2013.

\section{Preinterventional CMR analysis and real-time iCMR}

For preinterventional assessment, vascular and cardiac morphology and function was measured using appropriate CMR sequences as previously described $(1,17)$. Catheter and guidewire were navigated using real-time iCMR, with the alignment slices defined individually for each patient.

We used a dedicated real-time sequence (Beat-IRT, Siemens Healthcare, Erlangen, Germany) with the parameters below: Field of view $300 \mathrm{~mm}$, slice thickness 10-15 mm, TR $157.20 \mathrm{~ms}$, TE $1.31 \mathrm{~ms}$, flip angle $70^{\circ}$, image read out SSFP, acceleration factor 2 (GRAPPA), echo encoding steps 95 , echo train length 1 , averages 1 , 

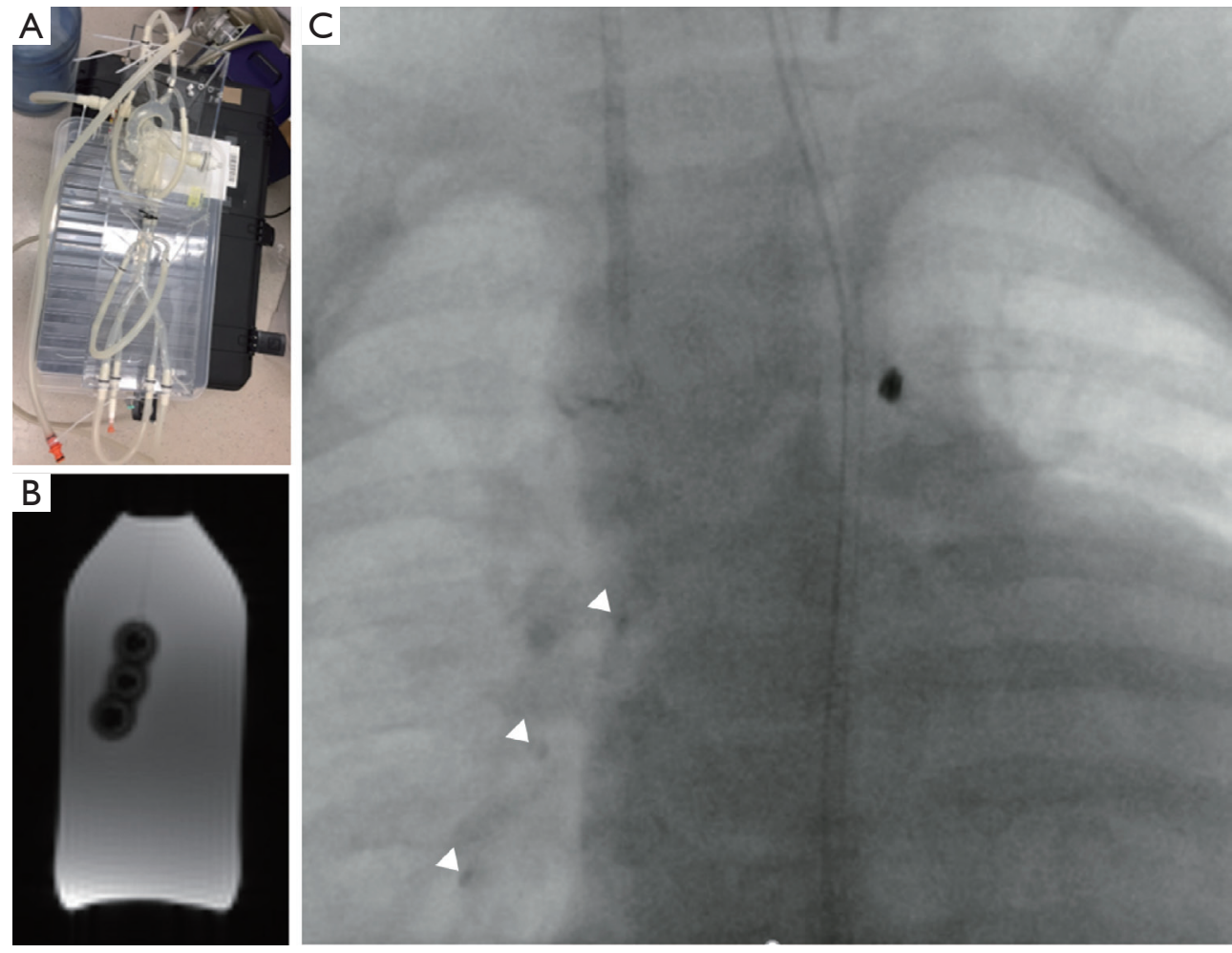

Figure 2 (A) Phantom for guidewire retrieval testes. (B) MR phantom with guidewire; signal void by the three markers on the guidewire. (C) Fluoroscopic image in an infant with partial cavo-pulmonary anastomosis; visualization of the three markers at the tip of the guidewire (white arrows).

bandwidth 1,488 Hz per pixel, temporal resolution 6.36 images per second and partial Fourier off.

\section{Endpoint of the PMCF trial}

The primary objective of the trial was to assess the device's safety and effectiveness in the intended procedures. Thus, the primary endpoint was defined as the success of the procedure achieved in the absence of device-related adverse events. The success was divided into three aspects, namely adequate handling, steerability and visualization. Success of the procedure implies that all three aspects mentioned above must be rated "yes" and no guidewire-related adverse events as damage to the vessel walls or other device-related events such as device failure, catheter obstruction by the guidewire, or non-visibility occurred. A positive evaluation of structural integrity of the guidewire was needed at the end of iCMR.

As a safety precaution, retrieval of the guidewire was trained in a phantom model (Elastrat, Geneva, $\mathrm{CH}$ ) using fragments that were intentionally cut from the wire. Typical conventional snares were used for the procedure and retrieval times in the phantom were about 1-2 minutes. Such procedures can be performed under X-ray control, as the tip of the wire is visible in the $\mathrm{X}$-ray image (Figure 2).

\section{Results}

A summary of all procedures is shown in Table 1 with diagnosis, regions of interest for cardiac catheterization by iCMR and the success of iCMR.

Twenty-five patients were recruited into the trial $(52 \%$ male, $48 \%$ female). Median age was 28.3 years; range $14.1-$ 79.0 (mean age 37 years; Table 2). Duration of the procedure was defined as the initial insertion of the guidewire into the patient until the guidewire was finally withdrawn from the individual. Procedure time on average was 19.0 minutes (median 15.0 minutes; range 2.0-45.0 minutes). In three out of $25(12 \%)$ of the patients, no further examination in the standard cath lab was indicated as all relevant clinical 
Table 1 Description of the participants and the success of the study

\begin{tabular}{|c|c|c|c|c|c|}
\hline Patient & Age (years) & Sex & Diagnosis & $\begin{array}{l}\text { Clinical question, } \\
\text { target pressure }\end{array}$ & Overall success \\
\hline$\# 1$ & 38 & Male & $\begin{array}{l}\text { Tricuspid atresia after modified Fontan-operation, RA- } \\
\text { RVOT homograft }\end{array}$ & RVP & Yes \\
\hline \#2 & 28 & Male & CoA, arterial hypertension & Pressure CoA & Yes \\
\hline \#3 & 14 & Male & $\begin{array}{l}\text { valvular AS and AR, Ross procedure, allograft, allograft } \\
\text { stenosis }\end{array}$ & $\begin{array}{l}\text { Pressure gradient } \\
\text { RVOT }\end{array}$ & Yes \\
\hline \#4 & 18 & Male & $\begin{array}{l}\text { Pulmonary atresia, ASD II, BTA, AP-Shunt, PCPC, TCPC } \\
\text { (extracardiac conduit), severe AR }\end{array}$ & $\begin{array}{l}\text { Pressure gradient } \\
\text { TCPC }\end{array}$ & Yes \\
\hline \#5 & 55 & Female & Chronic pulmonary embolism, PAPVR upper left PV & Pressure RA & Yes \\
\hline \#6 & 36 & Male & TOF, residual VSD, Shelhigh, Shelhigh stenosis, VSD & $\begin{array}{l}\text { RVP, pressure } \\
\text { gradient RVOT }\end{array}$ & Yes \\
\hline \#8 & 19 & Male & $\begin{array}{l}\text { PS, ASD II, valvuloplasty, transannular patch repair, ASD } \\
\text { closure, severe PR and RV dilation }\end{array}$ & RVP & Yes \\
\hline \#9 & 28 & Female & Situs inversus, azygos continuation, PAPVR, PAH & Pressure PA & $\begin{array}{l}\text { No (complex } \\
\text { morphology, PAH) }\end{array}$ \\
\hline \#10 & 45 & Male & $\begin{array}{l}\text { Ebstein's anomaly, TVR (bio), re-TVR (bio), VSD-closure, } \\
\text { paroxysmal atrial fibrillation, RBBB; TV (mean } 7 \text { mmHg), } \\
\text { residual VSD; TVR (interventional repair with Sapien valve) }\end{array}$ & Pressure RA and RVP & Yes \\
\hline \#11 & 78 & Female & $\begin{array}{l}\text { TOF; late VSD-closure, RV-PA-Conduit } \\
\text { (bioprothesis), coronary artery disease, CABG, atrial } \\
\text { fibrillation, RV-PA Stenosis }\end{array}$ & RVP, pressure PA & $\begin{array}{l}\text { No (high degree } \\
\text { IVC stenosis) }\end{array}$ \\
\hline \#15 & 26 & Female & $\begin{array}{l}\text { DORV (Taussig-Bing), TGA, CoA, PAB, Dilatation of re- } \\
\text { CoA. Kawashima operation, VSD-closure, ventricular } \\
\text { tachycardia, now: re-CoA }\end{array}$ & Pressure CoA & Yes \\
\hline \#16 & 28 & Female & $\begin{array}{l}\text { TAC, RPA- and LPA- stenosis; allograft, Infective } \\
\text { endocarditis, allograft replacement, angioplasty of RPA } \\
\text { and LPA, RPA- and LPA-stent; Now: intima proliferation in } \\
\text { the stent }\end{array}$ & RVP & Yes \\
\hline$\# 17$ & 24 & Male & AS; Ross-Procedure, now: enlarged RV, severe PR & RVP & Yes \\
\hline \#18 & 25 & Female & Ebstein's anomaly, severe TR & Pressure RA & Yes \\
\hline \#19 & 79 & Female & PDA, CoA & Pressure CoA & Yes \\
\hline \#20 & 20 & Female & $\begin{array}{l}\text { Ebstein's anomaly, Cone procedure, Now: Stenosis of } \\
\text { "Cone valve" }\end{array}$ & $\begin{array}{l}\text { Pressure gradient } \\
\text { RV/RA }\end{array}$ & Yes \\
\hline
\end{tabular}

Table 1 (continued) 
Table 1 (continued)

\begin{tabular}{lllll}
\hline Patient & Age (years) & Sex & Diagnosis & $\begin{array}{l}\text { Clinical question, } \\
\text { target pressure }\end{array}$ \\
\hline$\# 21$ & 46 & Female & ASD II & Pressure RA and RVP Yes \\
$\# 22$ & 17 & Male & DILV, PAB, pulmonary hypertension & Pressure RA and RVP Yes \\
$\# 23$ & 33 & Female & $\begin{array}{l}\text { Tricuspid atresia, Fontan-operation, conversion to TCPC } \\
\text { (extracardiac conduit) }\end{array}$ & Pressure gradient \\
$\# 24$ & 25 & Female & VSD & Pressure RA and RVP Yes \\
$\# 25$ & 63 & Male & Ebstein's anomaly, TR, PFO, arterial hypertension & Pressure RA and RVP Yes \\
\hline
\end{tabular}

AoA, ascending aorta; AP, aorto-pulmonary; AR, aortic regurgitation; AS, aortic stenosis; ASD, atrial septal defect; BTA, Blalock-Taussig anastomosis; CABG, coronary arterial by-pass graft; CoA, coarctation of the aorta; DILV, double inlet left ventricle; LPA, left pulmonary artery; PA, pulmonary artery; PAB, pulmonary artery banding; PAH, pulmonary arterial hypertension; PAPVR, partial anomalous pulmonary venous return; PCPC, partial cavo-pulmonary connection; PFO, persistent foramen ovale; PR, pulmonary regurgitation; PS, pulmonary stenosis; RA, right atrium; RPA, right pulmonary artery; RV, right ventricle; RVOT, right ventricular outflow tract; RVP, pressure right ventricle; TAC, truncus arteriosus communis; TCPC, total cavo-pulmonary connection; TGA, transposition of the great arteries; TOF, tetralogy of Fallot; TR, tricuspid regurgitation; TVR, tricuspid valve replacement; VSD, ventricular septal defect.

Table 2 Demographics of the study population and target region

\begin{tabular}{lc}
\hline Parameter & $\begin{array}{c}\text { Quantity: absolute } \\
\text { and percentage }\end{array}$ \\
\hline Age (median, range) & $28.3 ; 14.1-79.0$ \\
Female/Male & $12 / 13(48 \% / 52 \%)$ \\
Pressure measurement (primary target region) & \\
Right atrium & $8(32 \%)$ \\
Right ventricle & $17(68 \%)$ \\
Pulmonary artery & $5(20 \%)$ \\
Coarctation of the aorta & $3(12 \%)$ \\
Total cavo-pulmonary connection (TCPC) & $2(8 \%)$ \\
Patients reached primary endpoint & $23(92 \%)$ \\
\hline
\end{tabular}

queries and pressure assessments were addressed by iCMR. In all other patients, a sophisticated interventional cath lab catheter procedure was performed afterwards, which was not considered to be done by iCMR. The target of pressure monitoring for all subjects is presented in Table 2. It shows that most measurements were taken in the right ventricle $(\mathrm{n}=17)$ and in the right atrium $(\mathrm{n}=8)$.

Pressure data are not shown because single pressure measurements are not particularly relevant to the objective of this trial, which concentrates on the effectiveness and overall safety of the technique.

Twenty-three out of 25 subjects (92\%) successfully completed iCMR; in only two of 25 individuals could the target anatomical region not be reached with the catheterguidewire assembly because of complex anatomy, high pulmonary pressure and unknown stenosis of the inferior vena cava.

One patient (\#9), for example, had presented with complex CHD with situs inversus, partially abnormal pulmonary venous return, continuation of the azygos vein, and pulmonary arterial hypertension. Due to the complex anatomy and the high pulmonary pressure even with catheterization under fluoroscopy, there had been great advantages for cardiac catheterization. The main reason for the lack of success of the technique in this case was the complexity of the anatomy.

The second patient (\#11) presented with tetralogy of Fallot, late closure of a ventricular septal defect, bioprosthesis of the right ventricle to the pulmonary artery (RV-PA) with conduit stenosis, coronary artery disease after coronary bypass grafting and atrial fibrillation. During the procedure, a previously unknown advanced stenosis of the inferior vena cava was found, which couldn't be cleared with the catheter in iCMR due to an unfavorable angle of the inferior vena cava to the right atrium.

General anesthesia was only applied to the very first four of the 25 enrolled patients in this trial. As a result of the improvements in expertise and practice in the $\mathrm{iCMR}$ trial, the patients did not require sedation to complete the procedure.

Figures 3-5 illustrates the guidewire markers in various positions in three patients. The Berman catheter is imaged 


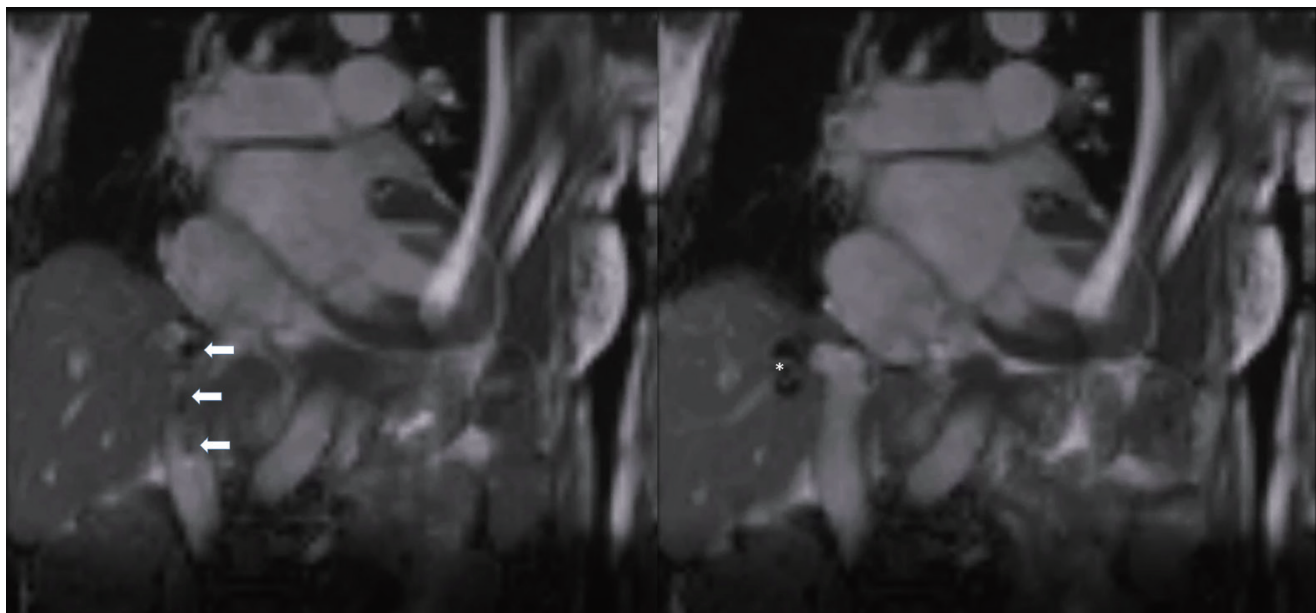

Figure 3 Case \#11, 78 years, female, tetralogy of Fallot, right ventricular to pulmonary artery conduit, late VSD-closure, coronary artery disease with coronary arterial bypass graft, RV-PA stenosis and atrial fibrillation; Target of iCMR: pressure of the right ventricular, pressure in the pulmonary artery; No success due to severe degree of stenosis of inferior vena cava at the level of the entrance to the right atrium. The three marks on the tip of the guidewire are located in the inferior vena cava (white arrows); balloon of Berman catheter inflated with $\mathrm{CO}_{2}$ in a liver vein (white asterix).

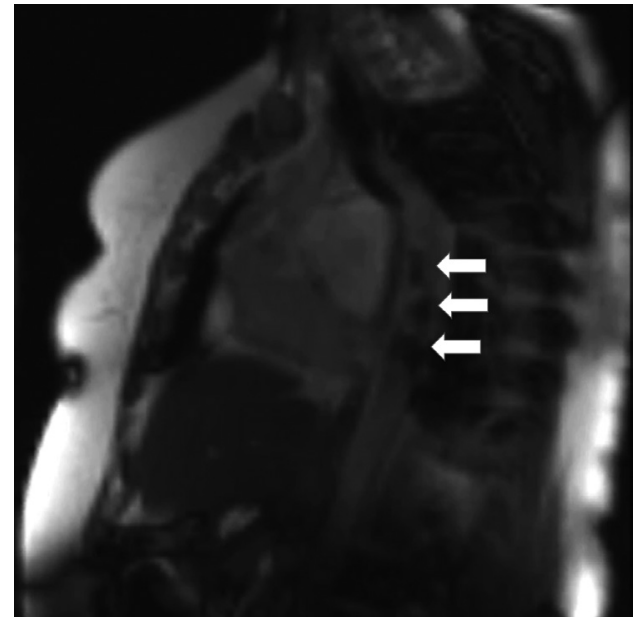

Figure 4 Case \#15, 26 years, female, double outlet right ventricle (DORV, Taussig-Bing), coarctation of the aorta (CoA), transposition of the great arteries, CoA-repair, pulmonary artery banding, reCoA with balloon dilatation. Corrective surgery (Kawashima), closure of the VSD, ventricular tachycardia. Now: re-CoA. Target of iCMR procedure: aortic arch with pressure measurement for pressure gradient assessment over the coarctation; Success: yes. Markers on guidewire in the descending aorta (white arrows).

separately by inflating the balloon with carbon dioxide (Figure 3).

The cumulative outcome of the procedures was $92 \%$.

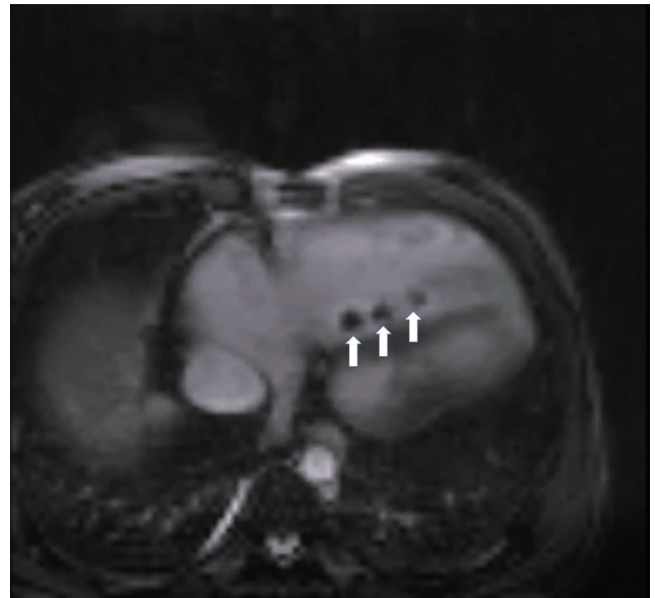

Figure 5 Case \#17, 24 years, male, aortic stenosis; Ross-surgery, now: right ventricle enlargement, severe pulmonary insufficiency. Target of iCMR: pressure in the right ventricle; Successful iCMR procedure. The tip of the guidewire with its markers is located in the right ventricle (white arrows).

No severe adverse events were reported in any of the 25 patients during the procedure, prior to their discharge or after 30 days of follow-up. Adverse events occurred in 11 of 25 patients (44\%) that were related to their disease status or to the procedure, but none of these events were related to the devices (catheter or guidewire) (Table 3). 
Table 3 Overview of adverse events, patient's reference number and the association with the procedure

\begin{tabular}{lcc}
\hline Adverse event & $\begin{array}{c}\text { Patient's reference } \\
\text { number (as in Table 1) }\end{array}$ & $\begin{array}{c}\text { Association to } \\
\text { the procedure }\end{array}$ \\
\hline $\begin{array}{l}\text { Hematoma in groin } \\
\text { Atrial fibrillation }\end{array}$ & $1,10,145$ & Yes \\
Pain in the groin & 18 & $\begin{array}{c}\text { No, pre-condition } \\
\text { of patient }\end{array}$ \\
$\begin{array}{l}\text { Pseudo aneurysm } \\
\text { groin, femoral artery }\end{array}$ & 25,2 & Yes \\
Pruritus & 8 & Yes \\
Diarrhea & 20 & No \\
Abdominal pain & 7 & No \\
Hypotension & 16 & No \\
Bradycardia & 16 & Yes \\
Sore throat & 16 & Yes \\
Vocal cord palsy & 16 & No \\
\hline
\end{tabular}

\section{Discussion}

The study demonstrated that invasive blood pressure and pressure gradients can be successfully assessed with liquidfilled catheters alone under iCMR guidance and with no need for a hybrid MR fluoroscopy suite. In the last decade, a number of research groups have performed these techniques using a hybrid suite. Tzifa et al. first reported on congenital interventions in men (6), Pushparajah et al. reviewed the 10 year experience of a single institution at Kings' College London (18) and Rogers et al. conducted a similar evaluation for the clinical work at the National Heart Lung and Blood Institute; National Institute of Health (NIH) (19). Pushparajah et al. also showed that pulmonary vascular resistance measured by iCMR catheterization allows accurate stratification for intervention in patients with CHD in a high volume study (20). Clinical work in these sites has opened the door for the creation of instruments for techniques such as right heart catheterization, MRI-guided biopsy, ablation and pressure assessment $(5,11,12,21-25)$. An MR-certified guidewire could be useful for most of these catheterization procedures. The availability of certified equipment has long been a major bottleneck in the iCMR community $(10,26)$. Recently Rogers et al. published a study of right heart catheterization by CMR fluoroscopy in 102 patients (25) and Ratnayaka et al. published 50 cases of right heart catheterization by CMR fluoroscopy with focus on feasibility and safety (27). Knight et al. showed that CMR-right heart catheterization can be incorporated into clinical practice for testing of pulmonary hypertension (24). In respect of these new promising studies we provide additional data of feasibility of iCMR by using a MRconditional guidewire.

The CE-marked guidewire evaluated in this trial was designed on the basis of a long process of development. It features a passive marking system with a set of discrete marks based on paramagnetic iron particles that have been optimized and applied to a different wire that has been used in animal studies for the placement of vena cava filters and renal and aortic stenting $(13,14)$.

The guidewire is a one body core-shaft-tip design as a safe-by-design follow-up of previously used guidewire (28). The findings demonstrate that the marks allow good visibility and dynamic control of the wire positioning, whereas the catheter tip can be additionally visualized by carbon dioxide $\left(\mathrm{CO}_{2}\right)$ inflated in the catheter balloon. It might also be possible to use balloons filled with gadolinium or using an alternate saturation pre-pulse in the real-time sequence that has be shown by different working groups $(5,29,30)$. Using a $\mathrm{CO}_{2}$-filled balloon that generates a signal void at the tip of the Berman catheter might be helpful, even when the guidewire markers itself also produce a signal void, since size and shape of the signal voids were of different shape.

Because we used straight-tipped guidewires according to the study design, we were unable to test the angled tip guidewires, which may have been beneficial for targeting more specific regions and may have been effective in the two cases in which the target region could not be accessed due to anatomical constraints. The balloon inflated with $\mathrm{CO}_{2}$ at the tip of the Berman catheter was also chosen to enhance overall visibility, as the guidewire markers often pass through the imaging slice faster than the inflated balloon tip at a slice thickness of 10 to $15 \mathrm{~mm}$. The closed tip Berman catheter was chosen only for safety reasons in this trial. Advanced iCMR procedures are only possible by pushing the tip of the guidewire outside of the catheter and to guide the catheter into the target region. One of the more promising advances of using a guidewire was the stiffening of the catheters in any required situation, as the catheters would become very smooth and floppy in the warm blood surrounding during the more advanced procedure duration. Using a real-time sequence, we were able to obtain an acceleration factor of 6 (GRAPPA), leading up to 11 frames per second (TR $94.32 \mathrm{~ms}$ ), but with 
reduced images quality.

Carrying out the vascular access in the MR room improved the overall procedure time and general acceptance of the study design. The total procedural time has improved as all study personnel have been increasingly customized with all of the steps in the MR setting over the course of time. The procedure time for the iCMR itself varied from 2 to 45 minutes, which was more dependent on the various anatomical and hemodynamic conditions and the selected target region for pressure assessment and not on the gain of experience during the trial.

We found procedural success in $92 \%$. No success of iCMR catheterization was only found in two patients (\#9, \#11), due to anatomic conditions. Despite the fact that the catheter examination was not successful, a solid basic examination could be performed by standard MRI. Three patients out of $25 \mathrm{did}$ not need an additional cathlab procedure, since all of the clinical questions could be answered by iCMR. Most of the patients had an additional procedure in the conventional cathlab, even when all questions could be answered by iCMR, because most of the additional procedures had an interventional focus under fluoroscopic guidance. Failing to reach the target region in two of 25 patients was also due the circumstance that we did not want to force catheterization over a stenotic region or in a complex cardiac condition. In general, other regions for vascular accesses are also possible, so that in patients with congenital heart defects, access via the radial artery or via the jugular vein may also be an option. For this study, only an access via the femoral vein/ artery was chosen. For this purpose, however, the patients must be positioned differently in the MRI scanner. The study was designed to provide highest safety condition for the patients involved. The experience gained during the study may guide further examinations.

For a successful future of cardiac catheterization in the MR-scanner for advanced interventions, the problem of how to treat severe unwanted complications in complex interventions must also be solved. First and foremost, heavy bleeding after a vessel or heart perforation by the catheter or guidewire is an essential problem, since the solution to this problem is often extremely time-critical in conventional cardiac catheterization laboratories. First of all, a good and fast visualization of the perforation site is essential, where MRI is limited by the current temporal resolution. Higher temporal resolution can only be bought by a worse image quality. Even for simple cardiac catheter examinations, there must always be a plan for handling a complication or a backup must be possible in the conventional catheter laboratory or by the heart surgeons. Furthermore, the right MR-compatible equipment must be available for these complications. With the further development of the iCMR, we hope to have more working tools at our disposal.

\section{Study limitations}

Although iCMR offers an inherent benefit in visualizing the position of the target chambers and vessels as well as the guidewire markers, only the catheter tip with its three markers could be visualized so far.

However, we believe that with safe MR guidewires and equipment, $\mathrm{iCMR}$ driven procedures may take their next step. Additional MR safe equipment as different safe catheter types and even more guidewires with different length, diameter and moreover different stiffness will hopefully follow. In the meantime, the next generation MRcompatible guidewire (Emery Glide ${ }^{\mathrm{TM}}$, Nano4Imaging, Düsseldorf, Germany) with Teflon coating and advanced gliding characteristics was released, but clinical data from this guidewire are still pending.

CMR and cardiac catheterization has been performed on a high level since years. Using the MR safe guidewire will help to steer the catheter to the region of interest. Simultaneous measurement of pressure/flow, pressure/ volume relationship and vascular resistance in CHD and pulmonary hypertension as a standard procedure in several centers will be feasible and may take iCMR to the next level of clinical routine and for new applications.

\section{Conclusions}

A MR-conditional guidewire assists in reaching targets in the heart and great vessels easily and at a high success rate. Therefore, invasive blood pressure measurement by CMR guidance by using fluid-filled catheters may be improved and interventional CMR may advance for a more routine procedure in future.

\section{Acknowledgments}

The authors are grateful to Sohrab Fratz, MD, PhD, who died in February 2016, for starting this study, his scientific enthusiasm and the profound scientific discussions.

Funding: Nano4Imaging (Düsseldorf, Germany) sponsored the PMCF study and provided the CE-marked guidewires for use in the MR environment. 


\section{Footnote}

Provenance and Peer Review: This article was commissioned by the Guest Editors (Yskert von Kodolitsch, Harald Kaemmerer, Koichiro Niwa) for the series "Current Management Aspects in Adult Congenital Heart Disease (ACHD): Part IV" published in Cardiovascular Diagnosis and Therapy. The article has undergone external peer review.

Reporting Checklist: The authors have completed the MDAR reporting checklist. Available at http://dx.doi.org/10.21037/ cdt-20-575

Data Sharing Statement: Available at http://dx.doi. org/10.21037/cdt-20-575

Conflicts of Interest: All authors have completed the ICMJE uniform disclosure form (available at http:// dx.doi.org/10.21037/cdt-20-575). The series "Current Management Aspects in Adult Congenital Heart Disease (ACHD): Part IV" was commissioned by the editorial office without any funding or sponsorship. Dr. Meierhofer reports personal fees and other from Nano4Imaging, Düsseldorf, Germany, during the conduct of the study; personal fees from Nano4Imaging, outside the submitted work. Dr. Belker reports other from Nano4Imaging, Düsseldorf, Germany, during the conduct of the study. Dr. Shehu reports other from Nano4Imaging, Düsseldorf, Germany, during the conduct of the study. Dr. Latus reports other from Nano4Imaging, Düsseldorf, Germany, during the conduct of the study. Dr. Mkrtchyan reports other from Nano4Imaging, Düsseldorf, Germany, during the conduct of the study. Dr. Naumann reports other from Nano4Imaging, Düsseldorf, Germany, during the conduct of the study. Dr. Stern reports other from Nano4Imaging, Düsseldorf, Germany, during the conduct of the study. Dr. Eicken reports other from Nano4Imaging, Düsseldorf, Germany, during the conduct of the study. Dr. Ewert reports other from Nano4Imaging, Düsseldorf, Germany, during the conduct of the study. The authors have no other conflicts of interest to declare.

Ethical Statement: The authors are accountable for all aspects of the work in ensuring that questions related to the accuracy or integrity of any part of the work are appropriately investigated and resolved. The study was approved by the ethical committee of the Technical University of Munich. The study is documented at ClinicalTrials.gov under identifier NCT02493634. All patients and parents gave their written consent to the study. The study was conducted in accordance with the Declaration of Helsinki (as revised in 2013).

Open Access Statement: This is an Open Access article distributed in accordance with the Creative Commons Attribution-NonCommercial-NoDerivs 4.0 International License (CC BY-NC-ND 4.0), which permits the noncommercial replication and distribution of the article with the strict proviso that no changes or edits are made and the original work is properly cited (including links to both the formal publication through the relevant DOI and the license). See: https://creativecommons.org/licenses/by-nc-nd/4.0/.

\section{References}

1. Fratz S, Chung T, Greil GF, et al. Guidelines and protocols for cardiovascular magnetic resonance in children and adults with congenital heart disease: SCMR expert consensus group on congenital heart disease. J Cardiovasc Magn Reson 2013;15:51.

2. Kilner PJ, Geva T, Kaemmerer H, et al. Recommendations for cardiovascular magnetic resonance in adults with congenital heart disease from the respective working groups of the European Society of Cardiology. Eur Heart J 2010;31:794-805.

3. Muthurangu V, Razavi RS. The value of magnetic resonance guided cardiac catheterisation. Heart 2005;91:995-6.

4. Muthurangu V, Taylor A, Andriantsimiavona R, et al. Novel method of quantifying pulmonary vascular resistance by use of simultaneous invasive pressure monitoring and phase-contrast magnetic resonance flow. Circulation 2004;110:826-34.

5. Ratnayaka K, Faranesh AZ, Hansen MS, et al. Real-time MRI-guided right heart catheterization in adults using passive catheters. Eur Heart J 2013;34:380-9.

6. Tzifa A, Krombach GA, Kramer N, et al. Magnetic resonance-guided cardiac interventions using magnetic resonance-compatible devices: a preclinical study and firstin-man congenital interventions. Circ Cardiovasc Interv 2010;3:585-92.

7. Tzifa A, Schaeffter T, Razavi R. MR imaging-guided cardiovascular interventions in young children. Magn Reson Imaging Clin N Am 2012;20:117-28.

8. Stern H, Seidenbusch M, Hapfelmeier A, et al. Increased Cancer Incidence Following up to 15 Years after Cardiac Catheterization in Infants under One Year between 1980 
and 1998-A Single Center Observational Study. J Clin Med 2020;9:315.

9. Razavi R, Hill DL, Keevil SF, et al. Cardiac catheterisation guided by MRI in children and adults with congenital heart disease. Lancet 2003;362:1877-82.

10. Lotz J. Interventional vascular MRI: moving forward. Eur Heart J 2013;34:327-9.

11. Campbell-Washburn AE, Rogers T, Stine AM, et al. Right heart catheterization using metallic guidewires and low SAR cardiovascular magnetic resonance fluoroscopy at 1.5 Tesla: first in human experience. J Cardiovasc Magn Reson 2018;20:41.

12. Campbell-Washburn AE, Ramasawmy R, Restivo MC, et al. Opportunities in Interventional and Diagnostic Imaging by Using High-Performance Low-Field-Strength MRI. Radiology 2019;293:384-93.

13. Kos S, Huegli R, Hofmann E, et al. Feasibility of realtime magnetic resonance-guided angioplasty and stenting of renal arteries in vitro and in Swine, using a new polyetheretherketone-based magnetic resonancecompatible guidewire. Invest Radiol 2009;44:234-41.

14. Kos S, Huegli R, Hofmann E, et al. MR-compatible polyetheretherketone-based guide wire assisting MRguided stenting of iliac and supraaortic arteries in swine: feasibility study. Minim Invasive Ther Allied Technol 2009;18:181-8.

15. Rube MA, Fernandez-Gutierrez F, Cox BF, et al. Preclinical feasibility of a technology framework for MRIguided iliac angioplasty. Int J Comput Assist Radiol Surg 2015;10:637-50.

16. World Medical A. World Medical Association Declaration of Helsinki: ethical principles for medical research involving human subjects. JAMA 2013;310:2191-4.

17. Fratz S, Hess J, Schuhbaeck A, et al. Routine clinical cardiovascular magnetic resonance in paediatric and adult congenital heart disease: patients, protocols, questions asked and contributions made. J Cardiovasc Magn Reson 2008;10:46.

18. Pushparajah KT, A.; Razavi, R. Cardiac MRI catheterization: A 10-year single institution experience and review. Interventional Cardiology (London) 2014;6:335-46.

19. Rogers T, Lederman RJ. Interventional CMR: Clinical applications and future directions. Curr Cardiol Rep 2015;17:31.

20. Pushparajah K, Tzifa A, Bell A, et al. Cardiovascular magnetic resonance catheterization derived pulmonary vascular resistance and medium-term outcomes in congenital heart disease. J Cardiovasc Magn Reson 2015;17:28.

21. Rogers T, Ratnayaka K, Karmarkar P, et al. Real-time magnetic resonance imaging guidance improves the diagnostic yield of endomyocardial biopsy. JACC Basic Transl Sci 2016;1:376-83.

22. Saikus CE, Lederman RJ. Interventional cardiovascular magnetic resonance imaging: a new opportunity for image-guided interventions. JACC Cardiovasc Imaging 2009;2:1321-31.

23. Rogers T, Ratnayaka K, Lederman RJ. MRI catheterization in cardiopulmonary disease. Chest 2014;145:30-6.

24. Knight DS, Kotecha T, Martinez-Naharro A, et al. Cardiovascular magnetic resonance-guided right heart catheterization in a conventional CMR environment predictors of procedure success and duration in pulmonary artery hypertension. J Cardiovasc Magn Reson 2019;21:57.

25. Rogers T, Ratnayaka K, Khan JM, et al. CMR fluoroscopy right heart catheterization for cardiac output and pulmonary vascular resistance: results in 102 patients. J Cardiovasc Magn Reson 2017;19:54.

26. Settecase F. M, Lillaney P., Losey A., Hetts S.W. MRguided Passive Catheter Tracking for Endovascular Therapy. Magn Reson Imaging Clin N Am 2015;23:591-605.

27. Ratnayaka K, Kanter JP, Faranesh AZ, et al. Radiationfree CMR diagnostic heart catheterization in children. J Cardiovasc Magn Reson 2017;19:65.

28. Krueger S, Schmitz S, Weiss S, et al. An MR guidewire based on micropultruded fiber-reinforced material. Magn Reson Med 2008;60:1190-6.

29. Velasco Forte MN, Pushparajah K, Schaeffter T, et al. Improved passive catheter tracking with positive contrast for CMR-guided cardiac catheterization using partial saturation (pSAT). J Cardiovasc Magn Reson 2017;19:60.

30. Faranesh AZ, Hansen $M$, Rogers $T$, et al. Interactive black blood preparation for interventional cardiovascular MRI. J Cardiovasc Magn Reson 2014;16:P32.

Cite this article as: Meierhofer C, Belker K, Shehu N, Latus H, Mkrtchyan N, Naumann S, Martinoff S, Stern H, Eicken A, Ewert P. Real-time CMR guidance for intracardiac and great vessel pressure mapping in patients with congenital heart disease using an MR conditional guidewire-results of 25 patients. Cardiovasc Diagn Ther 2021;11(6):1356-1366. doi: $10.21037 / \mathrm{cdt}-20-575$ 